\title{
Encapsulation efficiency and thermal stability of lemongrass (Cymbopogon citratus) essential oil microencapsulated by the spray-drying process
}

\author{
${ }^{1,2}$ Nguyen, P.T.N., ${ }^{1,2}$ Vo, T.T., ${ }^{1,2}$ Tran, T.Y.N., ${ }^{3}$ Le, T.H.N., ${ }^{4}$ Mai, H.C., ${ }^{5}$ Tran, T.T. and \\ ${ }^{1,2 *}$ Long, G.B. \\ ${ }^{1}$ Center of Excellence for Biochemistry and Natural Products, Nguyen Tat Thanh University, Ho Chi Minh \\ City, Vietnam \\ ${ }^{2}$ NTT Hi-Tech Institute, Nguyen Tat Thanh University, Ho Chi Minh City, Vietnam \\ ${ }^{3}$ Department of Chemical Engineering, HCMC University of Technology, VNU-HCM, Ho Chi Minh City, \\ Vietnam \\ ${ }^{4}$ Department of Chemical Engineering \& Processing, Nong Lam University of Ho Chi Minh City, Viet Nam \\ ${ }^{5}$ Food Technology Department, College of Agriculture, Can Tho University, Can Tho City, Vietnam
}

\section{Article history: \\ Received: 27 June 2020 \\ Received in revised form: 14 \\ August 2020 \\ Accepted: 21 September 2020 \\ Available Online: 12 \\ December 2020 \\ Keywords: \\ Microencapsulation, \\ Lemongrass (Cymbopogon \\ citratus), \\ Essential oil, \\ Oil retention}

DOI:

https://doi.org/10.26656/fr.2017.5(1).300

\begin{abstract}
Encapsulation is a potential technique that is widely studied and applied in the preservation of biological compounds and living cells. Lemongrass (Cymbopogon citratus) essential oil is a biological compound that emits a strong aroma and contains robust antibacterial compounds, hence its applications in various areas such as food, pharmaceuticals and cosmetics. However, lemongrass essential oil is in a liquid form, so it is easy to evaporate and oxidize when being exposed to temperature variations, oxygen, and light. Hence, the present study was aimed to determine the effects of heating temperature and time on the stability of microencapsulated lemongrass essential oil powder. In this research, microencapsulated powder was produced by the spray-drying method using maltodextrin $(30 \%, \mathrm{w} / \mathrm{w})$ as the wall material and lemongrass $(1.5 \%, \mathrm{w} / \mathrm{w})$ as the core material. Thereafter, the effects of heat during processing, including temperature $\left(60^{\circ} \mathrm{C}\right.$ to $\left.180^{\circ} \mathrm{C}\right)$ and treatment time (from 20 to 80 mins) were evaluated. The results showed that when the temperature and the time increased, the color of powder became darker and OR values were rapidly reduced. The selected optimal temperature and time was $100^{\circ} \mathrm{C}$ and 20 mins. The encapsulated essential oil maintained its main components including nerol, citral a, citral b, and geraniol, even after being heated.
\end{abstract}

\section{Introduction}

Nowadays, studies on plants natural compounds have become more extensive because they contain many biological compounds (Alitonou et al., 2006). The Cymbopogon genus is an aromatic tall grass with long, thin leaves. It originated in India and is grown in countries such as Vietnam, China, Thailand and West India. Moreover, it is found in tropical and subtropical regions of Asia, Africa and America (Lonkarbr et al., 2013). This genus includes approximately 140 species and is applied in many different areas such as food, cosmetics and medicine (Chanthai et al., 2012). The lemongrass leaves can be used to produce tea or powders. Furthermore, one of the most popular products derived from lemongrass is essential oil (Eos) extracted using many different methods: steam distillation, hydrodistillation and microwave-assisted distillation
(Hien et al., 2018). Beside main components such as citral and geraniol, lemongrass EO also contains various compounds such as $\beta$-caryophyllene, limonene, geranyl acetate, methyl eptanone and linalool, depending on environmental, genetic, and geographic conditions (Khanuja et al., 2005; Xu et al., 2013).

Many studies have shown that lemongrass EO exhibited antimicrobial, anti-inflammatory, anticancer and allelopathic properties (Alitonou et al., 2006; Kumar et al., 2008). However, lemongrass EO is a volatile compound so it is susceptible to change and lost when exposed to external environments such as light, temperature or oxygen. One of the popular technologies used to increase the stability of lemongrass EO is microencapsulation because it could prevent chemical reactions and limit the loss of these components in lemongrass EO (Zanetti et al., 2018). 
Microencapsulation technologies include physical processes (such as spray chilling/cooling, spray drying and extrusion) and chemical processes (such as coacervation, molecular inclusion, co-crystallization, and interfacial or in situ polymerization) (Schapoval et al., 2010).

In recent years, spray-drying microencapsulation has become a favorable method due to low cost and the ability to protect the contained oils against ambient conditions, including temperature, light, oxygen and humidity without causing changes or loss of the oil's quality (Veiga et al., 2019; Assadpour and Jafari, 2019). For example, a study conducted by Tomazeli Junior et al. (2018) showed that spray-drying of essential thyme oils did not result in any changes in the chemical compounds and antimicrobial activity of this EO. Another study by Granados-Vallejo et al. (2019) also proposed that the shelf-life and stability of green coffee oils have been improved upon spray-drying microencapsulation. Of all the factors that determine the efficiency of spray-drying, temperature and time length of processing and preservation are known to play a significantly important role; as studies have shown that high temperature within a prolonged period of time can readily damage the wall material of the encapsulates (Dunstan et al., 2002; Tonon et al., 2010; Sun et al., 2020). However, up to the present, there has not been any research to examine the effects of these factors on the stability of microencapsulated powders, especially microencapsulated lemongrass EO powders.

Therefore, in this study, the effects of the temperature and time of spray-drying microencapsulation on lemongrass EO were investigated and evaluated in terms of the retention of lemongrass EO (OR), the powder color, the chemical composition and the powder particle morphology.

\section{Materials and methods}

\subsection{Chemicals and reagents}

Lemongrass EO obtained from Tien Giang province, Vietnam was distilled using the steam distillation method and purified using the fractional distillation method. Maltodextrin (12DE, Roquette, France) were used as the materials. Tween 80 (Xilong, China) were used as an emulsifier.

\subsection{Microencapsulation by spray-drying}

The process of EO microencapsulation was based on the methodology of Saénz (2009) with modifications. Maltodextrin as the wall material was dissolved in distilled water at a concentration of $30 \%$ solids. This solution was kept for $12 \mathrm{hrs}$ at room temperature to allow the polymer molecules to completely saturate. Then, the emulsions were prepared by adding lemongrass EO and Tween 80 with an amount equal to $5 \%$ weight of essential oil. The dispersions were homogenized using a basic homogenizer (Ultra-Turrax IKA T18, Wilmington, North Carolina, USA) with stirring at $6000 \mathrm{rpm}$ for 20 mins. These emulsions were dried with spray-dryer equipment (YC-015; Shanghai Pilotech Instrument and Equipment Co., Ltd, Shanghai, China) equipped with a two-fluid nozzle atomizer. The process was performed under the inlet temperature of $140^{\circ} \mathrm{C}$ and feed rate of 120 $\mathrm{mL} / \mathrm{h}$. The obtained powder was collected and stored in sealed glass bottles at $25^{\circ} \mathrm{C}$ for further analysis.

\subsection{Thermal treatment}

The obtained powder was measured for moisture content before applying thermal treatment. A total of forty-eight aluminum plates $(10 \mathrm{~cm}$ in diameter) was prepared, put in $25 \mathrm{~g}$ of microencapsulated lemongrass EO powder and uncovered. All plates were subjected to heating under various temperature levels $(60,100,140$, $180^{\circ} \mathrm{C}$ ) in a drying oven (Memmemert UN55, Schwabach, Germany). At each the temperature levels, after a period of 20,40,60 and 80 mins, the samples were removed, cooled and weighed. The microencapsulated products were determined for oil retention (OR) by distilling the microencapsulated powder in a Clevenger-type apparatus for $4 \mathrm{hrs}$. The EO was extracted from the water phase using ethyl ether. All experiments were conducted three times.

\subsection{Characterization of the microcapsules}

\subsubsection{Moisture content}

The moisture content of microencapsulated lemongrass essential powder was estimated by drying at $105^{\circ} \mathrm{C}$ in the oven (Vord-460-D, Thermoline Scientific Equipment Pty Ltd., NSW, Australia) to constant weight using the method of AOAC International (1995).

\subsubsection{EO retention $(O R)$}

The OR of microencapsulated powder before and after the heating process was calculated by diluting the microencapsulated powder before and after heating for 4 hrs in a Clevenger-type apparatus and applying the following equation:

$$
\text { Oil retention }(\%)=\frac{X}{Y}
$$

Where:

$\mathrm{X}(\mathrm{mL} / \mathrm{g})=\underline{\text { volume of lemongrass essential oils in powders after heating }(\mathrm{mL})}$ weight of dry matter after heating (gram) $\mathrm{Y}(\mathrm{mL} / \mathrm{g})=\frac{\text { volume of lemongrass essential oils in powders before heating }(\mathrm{mL})}{\text { weight of }}$ 


\subsubsection{Identification of EO components}

The chemical composition of the EO samples was analyzed by a SCION SQ gas chromatograph (Bruker Daltonics Inc., Billerica, MA, USA) equipped with a Rxi -5MS capillary column ( $30 \mathrm{~m} \times 0.25 \mathrm{~mm}$, film thickness $0.25 \mu \mathrm{m})$ (Restek, Bellefonte, PA, USA). The temperature of the injector was adjusted at $250^{\circ} \mathrm{C}$. Helium was the carrier gas with a constant flow rate of 1 $\mathrm{mL} / \mathrm{min}$.

\subsubsection{Particle morphology determination}

The particle morphology was determined using scanning electron microscopy (SEM). Samples were directly deposited on carbon conductive tape on aluminum SEM stubs and were coated with a thin gold layer using gold sputtering.

\subsubsection{Color measurement}

Color of powders after the heating process was measured using colorimeter (DP-9000, Hunter Associates Laboratory, Reston, VA, USA) fitted with an aperture (25 $\mathrm{mm}$ in diameter). Lightness (L), redness (a) and yellowness (b) as well as darkness (Lo), greenness (ao) and blueness (bo) were determined to calculate the total color difference using the equation as described previously (Saenz et al., 2009; Sarpong et al., 2019; AlGhamdi et al., 2020).

\subsection{Statistical analysis}

All experiments were conducted in triplicates. The data were expressed in mean \pm standard deviation (SD) and obtained from two-way ANOVA (Statgraphics Technologies Inc., The Plains, VA, USA) with the level of significance at $5 \%$.

\section{Results and discussion}

\subsection{Properties of lemongrass essential oils}

Lemongrass EO is a viscous liquid with dark yellow or dark amber color. GC-MS analysis has shown the presence of 9 compounds accounting for $89.949 \%$ of the total EO. The major components were citral $(49.076 \%)$, myrcene $(30.492 \%)$, farnesol $(1.898 \%)$, piperitone $(0.627 \%)$, limonene $(0.299 \%)$ and 6-methyl-5-hepten-2one $(1.460 \%)$ while the minor components were geraniol $(3.762 \%)$ and citronella $(2.335 \%)$. The quality of lemongrass EO is generally determined by its citral content (Mohamed Hanaa et al., 2012). Citral (3,7dimethyl-2,6- octadienal) is used as a starting material for manufacturing perfumes in cosmetics and flavoring in the food industry. Nerol is used for bouquetting citrus flavor (Joy et al., 2006). Myrcene, geraniol, linalool and citronellol separated from lemongrass oil can be used in fragrance and flavoring production (Fahlbusch et al., 2003; Lasekan and Lasekan, 2012). Comparing with the chemical constituents of this lemongrass EO with the previous study by Tajidin (2012), its composition was relatively similar to that of Indian oils, with the same content of citral and geraniol. The result also indicated a high percentage of myrcene content in the oil $(30.492 \%)$ which is similar to the study in West Indian lemongrass EO (Skaria et al., 2006). Boukhatem et al. (2013) has also shown similar results when extracting EO from lemongrass leaves, in which the main constituents included geranial $(28.93 \%)$, neral $(24.30 \%)$, and myrcene $(23.92 \%)$.

\subsection{Properties of lemongrass essential oils}

The color of microencapsulated lemongrass EO powders at different temperatures and time was shown in Table 1.

Between 60 and $100^{\circ} \mathrm{C}$, the powder color retained its characteristic white color after drying. However, when the temperature increased from $140-180^{\circ} \mathrm{C}$, the color significantly changed into darker yellow. Similarly, the powder color also became dark yellow as the treatment time prolonged.

The color of microencapsulated EO powders influenced by heating temperature and time were shown in Table 2. It is clear that $b$ value of color parameter achieved the highest range value (app. 13.4 \pm 0.086 ) and the $\mathrm{L}$ values reduce increasingly (app. $95.310 \pm 0.923$ ) at $180^{\circ} \mathrm{C}$. These results revealed that the microencapsulated powders would have a deep yellow color than at $60^{\circ} \mathrm{C} \mathrm{(b}$ value app. 7.827 \pm 0.174 , $\mathrm{L}$ value $99.176 \pm 0.570$ ). Figure 1 displayed the change of TCD values at different time and temperatures. The TCD values increased rapidly from 0.768 to 7.007 , comparing with the control sample when changing temperatures from 140 to $180^{\circ} \mathrm{C}$. In contrast, from 60 to $100^{\circ} \mathrm{C}$, TCD values were not significantly

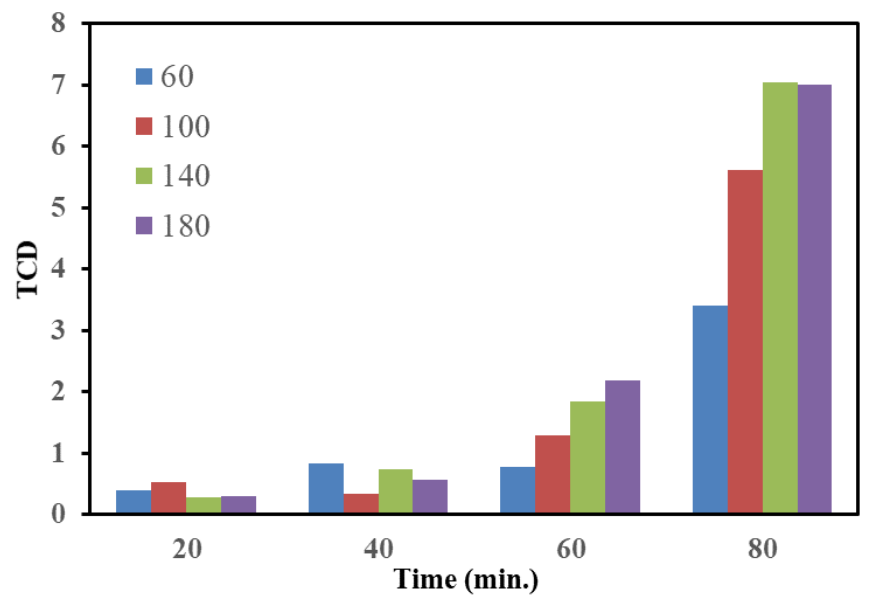

Figure 1. Total color difference values of lemongrass EO at different time points and temperatures as compared to the control sample. 
Table 1. Image of color of microencapsulated lemongrass EO powders at different temperature and time

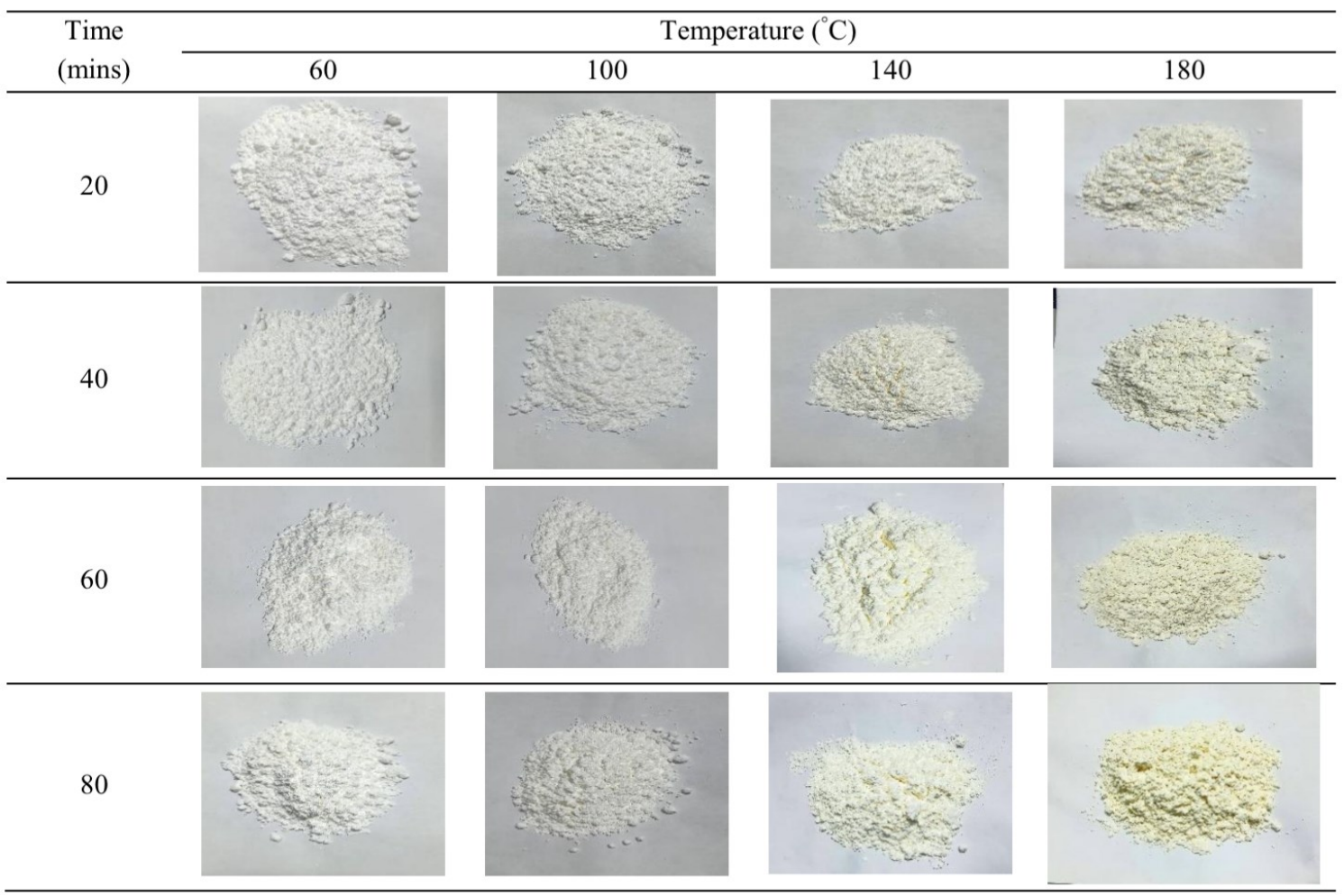

Table 2. Effects of temperature and treatment time on lemongrass EO powder color.

\begin{tabular}{cccccc}
\hline Temperature $\left({ }^{\circ} \mathrm{C}\right)$ & Time (min) & L value & TCD & a value & b value \\
\hline Control sample & 0 & $99.46 \pm 0.553$ & 0 & $-5.72 \pm 0.066$ & $7.78 \pm 0.025$ \\
\hline \multirow{2}{*}{$60^{\circ} \mathrm{C}$} & 20 & $99.213 \pm 0.898$ & 0.391 & $-5.630 \pm 0.000$ & $8.070 \pm 0.138$ \\
& 40 & $99.106 \pm 0.775$ & 0.529 & $-5.617 \pm 0.029$ & $8.160 \pm 0.252$ \\
& 60 & $99.203 \pm 0.143$ & 0.289 & $-5.617 \pm 0.029$ & $7.863 \pm 0.274$ \\
& 80 & $99.176 \pm 0.570$ & 0.3 & $-5.633 \pm 0.076$ & $7.827 \pm 0.174$ \\
\hline \multirow{3}{*}{$100^{\circ} \mathrm{C}$} & 20 & $98.706 \pm 1.352$ & 0.825 & $-5.610 \pm 0.114$ & $8.097 \pm 0.451$ \\
& 40 & $99.133 \pm 0.783$ & 0.345 & $-5.610 \pm 0.075$ & $7.803 \pm 0.146$ \\
& 60 & $98.853 \pm 1.371$ & 0.733 & $-5.643 \pm 0.052$ & $8.183 \pm 0.534$ \\
$140^{\circ} \mathrm{C}$ & 80 & $99.220 \pm 0.495$ & 0.575 & $-5.640 \pm 0.089$ & $8.297 \pm 0.359$ \\
\hline & 20 & $98.950 \pm 0.935$ & 0.768 & $-5.680 \pm 0.114$ & $8.353 \pm 0.425$ \\
& 40 & $99.110 \pm 0.886$ & 1.292 & $-5.687 \pm 0.052$ & $9.023 \pm 0.502$ \\
& 60 & $98.580 \pm 0.366$ & 1.84 & $-5.630 \pm 0.099$ & $9.393 \pm 0.436$ \\
& 80 & $98.426 \pm 0.404$ & 2.178 & $-5.660 \pm 0.049$ & $9.697 \pm 0.245$ \\
\hline & 20 & $97.873 \pm 0.207$ & 3.407 & $-5.540 \pm 0.000$ & $10.790 \pm 0.504$ \\
& 40 & $96.466 \pm 0.669$ & 5.603 & $-5.323 \pm 0.038$ & $12.500 \pm 0.489$ \\
& 60 & $95.373 \pm 0.567$ & 7.045 & $-5.143 \pm 0.076$ & $13.490 \pm 0.345$ \\
& 80 & $95.310 \pm 0.923$ & 7.007 & $-5.177 \pm 0.038$ & $13.400 \pm 0.086$ \\
\hline
\end{tabular}

changed. The situation can be explained by browning reactions or caramelization of sugars, which has also been found in the study of Quek et al. (2007), Sachin et al. (2010) and Chong and Wong (2015) when conducting spray-dried Sapodilla (Manilkara zapota), watermelon, ginger powders, respectively.

\subsection{Properties of lemongrass essential oils}

The effects of heating temperature and time on OR of encapsulated lemongrass EO powder were demonstrated in Figure 2.

As shown in Figure 2, treatment temperature and time had significant effects on the OR values of the microencapsulation powder $(\mathrm{p}<0.05)$. When the temperature increased from 60 to $180^{\circ} \mathrm{C}$ and the treatment time increased from 0 to $80 \mathrm{mins}$, the OR values decreased. Although the decrease in OR values seemed insignificant during the first 20 mins of treatment time $\left(60^{\circ} \mathrm{C}: 92.854 \%, 100^{\circ} \mathrm{C}: 92.015 \%, 140^{\circ} \mathrm{C}: 80.722 \%\right.$ and $180^{\circ} \mathrm{C}: 67.523 \%$ ), it tended to continue drastically towards the end of the heating process $\left(60^{\circ} \mathrm{C}: 79.051 \%\right.$, $100^{\circ} \mathrm{C}: \quad 65.953 \%, \quad 140^{\circ} \mathrm{C}: \quad 53.800 \%$ and $180^{\circ} \mathrm{C}$ : $27.153 \%)$.

The inclusion of essential oils in cyclic 
oligosaccharides or oligosaccharides (e.g. $b$ cyclodextrin, maltodextrin) was proposed to improve the stability and decrease its volatility and degradation (Schapoval et al., 2010). When the temperature was increased up to $100^{\circ} \mathrm{C}$, moisture moves by diffusion to the surface of the particles and drags the EO along with it, leading to reduced OR values (Rulkens and Thijssen, 2007). The increasing temperature may also associate with accelerated chemical reactions and formation of free radicals which leads to autoxidation and hydroperoxides decomposition (Choe and Min et al., 2006). The van's Hoff law expresses that chemical reaction rates increase approximately doubles when the temperature rises by $10^{\circ} \mathrm{C}$, Abdul Aziz et al. (2015) discussed a temperature effect on microencapsulation of other Eos. Recently, the researchers were pointed out that the effects of spray-drying temperature and treatment time on other Eos (Obón et al., 2009). The above results have shown the efficiency of the microencapsulation lemongrass EO by spray-drying technique using maltodextrin as wall material to help to enhance the product thermal stability. Nevertheless, as mentioned above, higher temperature $\left(140-180^{\circ} \mathrm{C}\right)$ could cause browning reactions or caramelization of sugars, leading to the destruction of wall material and loss of EO inside (Miao and Roos, 2004; Nunes and Mercadante, 2007). Therefore, it was necessary to select an appropriate processing and storage temperature for the product. The combination of data obtained from the color measurement and OR values of microencapsulated powders suggested that the suitable temperature for maintaining the stability of microencapsulated lemongrass essential oil powder must be below $100^{\circ} \mathrm{C}$ in 20 mins; OR value observed at $92.015 \%$ after 20 mins.

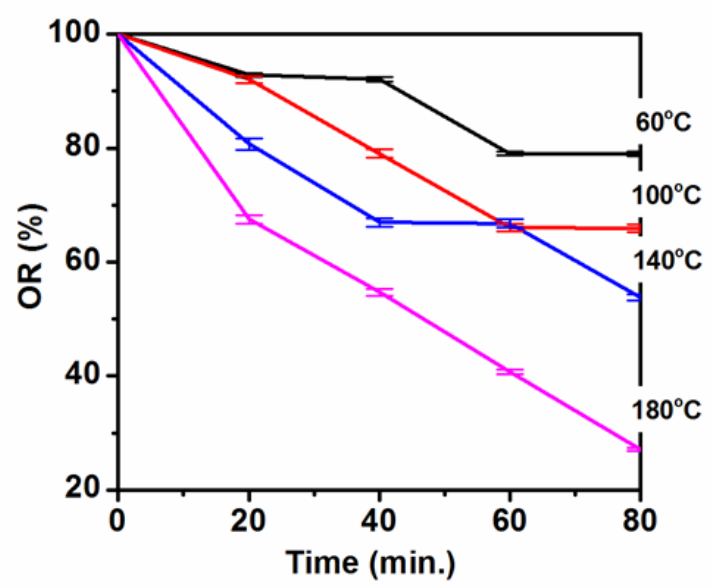

Figure 2. Effect of heating temperature and time on OR of lemongrass EO.

\subsection{Properties of lemongrass essential oils after thermal treatment}

The properties of lemongrass essential oils after heating at $100^{\circ} \mathrm{C}$ in 20 mins were analyzed by gas chromatography-mass spectrometry (GC-MS). Table 3 compares the composition of lemongrass essential oil in powders before and after heated at $100^{\circ} \mathrm{C}$ in 20 mins.

Table 3. Compositions of Lemongrass EO before and after thermal treatment

\begin{tabular}{lcc}
\hline \multicolumn{1}{c}{ Compounds } & $\begin{array}{c}\text { Content before } \\
\text { heating } \\
(\%)\end{array}$ & $\begin{array}{c}\text { Content after } \\
\text { heating } \\
(\%)\end{array}$ \\
\hline Myrcene & 30.492 & 17 \\
Citral & 49.076 & 37.634 \\
Geraniol & 3.762 & 1.589 \\
Farnesol & 1.898 & 0.309 \\
Piperitone & 0.627 & 2.684 \\
Citronella & 2.335 & 4.681 \\
Limonene & 0.299 & 0.255 \\
6-methyl-5-hepten-2-one & 1.46 & 1.061 \\
\hline \multicolumn{1}{c}{ Total } & 89.949 & 65.213 \\
\hline
\end{tabular}

Analysis of lemongrass EO composition after heating process showed that the main compounds included: citral (37.634\%), myrcene (17\%), geraniol $(1.589 \%)$, citronella $(4.681 \%)$ and limonene $(0.255 \%)$. Despite the general decline of all components upon heat application at $100^{\circ} \mathrm{C}$ in 20 mins, except for piperitone and citronella, the content of citral and myrcene remained the highest. When heating up to $100^{\circ} \mathrm{C}$, moisture moved by diffusion to the surface of the particles and drags along the EO. Loss of citral on this study was related to its volatility since no additional peaks were found on chromatograms. Shahpour et al. (2008) found that as the drying temperature increases, the content of monoterpenes in EO gradually decreased while sesquiterpenes increased to a noticeable amount. This may be due to the low molecular weight of monoterpenes in comparison with sesquiterpenes, which would leave the particles more rapidly at high temperature. In addition, certain heat-sensitive terpenoid classes, particularly terpenes and aldehydes, are also prone to structural transformations occurring at elevated temperatures (Turek and Stintzing, 2013). Tomaino et al. (2005) reported that heating has caused terpenic conversion reactions to the EO. Microencapsulation is an advanced technology which helps to protect biocompounds against the heat effect. According to the obtained results, the uses of wall material made of maltodextrin combined with spray-drying technology increased the durability of compounds in lemongrass EO under heating conditions.

\subsection{Powder morphology}

Morphology of the powder particles after heating at $100^{\circ} \mathrm{C}$ in 20 mins and control sample (not heated) were shown in Figure 3. The two samples have similar concentrations of wall material $(30 \% \mathrm{w} / \mathrm{w})$ and core 
material $(1.5 \% \mathrm{w} / \mathrm{w})$. The particles from two obtained powders had various sizes. However, in terms of morphology, most of the particles have a rounded external surface and no apparent fissures or cracks, which plays an important role in the protection and core retention (Carneiro et al., 2013). In addition, particle surfaces were also shriveled and concave, as reported previously (Rajabi et al., 2015). Increasing temperature also led to faster water evaporation and formation of the particles with a smooth surface, although not clearly observed in Figure 3b (Alamilla-Beltrán et al., 2005). In this study, the heating process has been conducted within a short period of time (20 mins) and OR values have not decreased significantly (about $8 \%$ ). Thus, no significant changes in particle size and surface were visualized after heating.
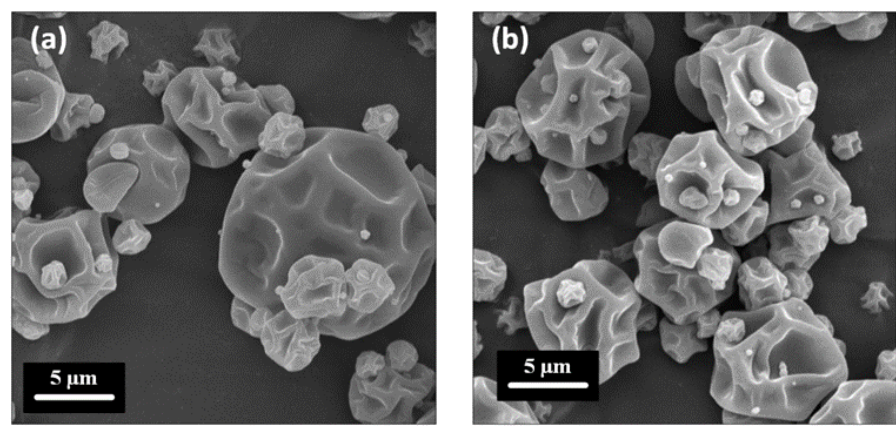

Figure 3. SEM observation of the particles containing lemongrass EO using maltodextrin as wall materials after heating at $100^{\circ} \mathrm{C}$ in 20 mins. (a) Control sample and (b) Heated sample.

\section{Conclusion}

Lemongrass EO has been widely used in folk medicine for the treatment of anxiety, memory deficit, and cancer thanks to its high antioxidant activity and antibacterial properties. Therefore, this study determined the effects of temperature and heating time on microencapsulated lemongrass essential oil based on the retention of lemongrass EO (OR), powder color, the chemical composition and particle morphology after the heating process. The lemongrass EO was successfully microencapsulated with maltodextrin as a carrier material by using spray drying. After heating was completed, the EO was obtained using hydro-distillation and analyzed by GC-MS. The decrease of color was observed in all powder samples after thermal treatment. Besides, high temperature also results in a reduction of OR values. The lowest OR $(27.153 \%)$ was observed at powder subjected to thermal treatment of $180^{\circ} \mathrm{C}$ in 80 mins. Optimal temperature and time were selected as $100^{\circ} \mathrm{C}$ and 20 mins, respectively. However, the phytochemical screening of lemongrass EO before and after heating revealed the major presence of citral, myrcene, geraniol and citronella. The SEM image showed that all the samples have similar morphology and most of the particles have a rounded external surface and no apparent fissures or cracks. The microencapsulation process is proven to be highly effective in preserving the active substances present in lemongrass EO after heating.

\section{Conflict of interest}

The authors declare no conflict of interest.

\section{Acknowledgements}

This study was supported by Tien Giang Department of Science and Technology, Tien Giang Province, Vietnam under the grant number 103/HĐ-QPTKH\&CN.

\section{References}

Abdul Aziz, F.R., Jai, J., Raslan, R. and Subuki, I. (2015). Microencapsulation of essential oils application in textile: A review. Advanced Materials Research, 1113, 346-351. https://doi.org/10.4028/ www.scientific.net/AMR.1113.346

Alamilla-Beltrán, L., Chanona-Pérez, J.J., JiménezAparicio, A.R. and Gutiérrez-López, G.F. (2005). Description of morphological changes of particles along spray drying. Journal of Food Engineering, 67 (1-2), 179-184. https://doi.org/10.1016/ j.jfoodeng.2004.05.063

Al-Ghamdi, S., Hong, Y.-K., Qu, Z. and Sablani, S.S. (2020). State diagram, water sorption isotherms and color stability of pumpkin (Cucurbita pepo L.). Journal of Food Engineering, 273, 109820. https:// doi.org/10.1016/j.jfoodeng.2019.109820

Alitonou, G., Avlessi, F., Sohounhloue, D., Agnaniet, H., Bessiere, J. and Menut, C. (2006a). Investigations on the essential oil of Cymbopogon giganteus from Benin for its potential use as an anti-inflammatory agent. International Journal of Aromatherapy, 16(1), 37-41. https://doi.org/10.1016/j.ijat.2006.01.001

Assadpour, E. and Jafari, S.M. (2019). Advances in spray-drying encapsulation of food bioactive ingredients: From microcapsules to nanocapsules. Annual Review of Food Science and Technology, 10, 103-131. https://doi.org/10.1146/annurev-food032818-121641

Boukhatem, M.N., Ferhat, M.A., Kameli, A., Saidi, F. and Kebir, H.T. (2014). Lemon grass (Cymbopogon citratus) essential oil as a potent anti-inflammatory and antifungal drugs. Libyan Journal of Medicine, 9 (1), 25431. https://doi.org/10.3402/ljm.v9.25431

Carneiro, H.C.F., Tonon, R.V., Grosso, C.R.F. and Hubinger, M.D. (2013). Encapsulation efficiency and oxidative stability of flaxseed oil microencapsulated by spray drying using different 
combinations of wall materials. Journal of Food Engineering, 115(4), 443-451. https:// doi.org/10.1016/j.jfoodeng.2012.03.033

Chanthai, S., Prachakoll, S., Ruangviriyachai, C. and Luthria, D.L. (2012). Influence of extraction methodologies on the analysis of five major volatile aromatic compounds of citronella grass (Cymbopogon nardus) and lemongrass (Cymbopogon citratus) grown in Thailand. Journal of AOAC International, 95(3), 763-772. https:// doi.org/10.5740/jaoacint.11-335

Choe, E. and Min, D.B. (2006). Mechanisms and factors for edible oil oxidation. Comprehensive Reviews in Food Science and Food Safety, 5(4), 169-186. https://doi.org/10.1111/j.1541-4337.2006.00009.x

Chong, S.Y. and Wong, C.W. (2015). Production of spray-dried sapodilla (Manilkara zapota) powder from enzyme-aided liquefied puree: Sapodilla fruit powder production. Journal of Food Processing and Preservation, 39(6), 2604-2611. https:// doi.org/10.1111/jfpp. 12510

Dunstan, D. W., Zimmet, P.Z., Welborn, T.A., de Courten, M.P., Cameron, A.J., Sicree, R.A., Dwyer, T., Colagiuri, S., Jolley, D., Knuiman, M., Atkins, R. and Shaw, J.E. (2002). The rising prevalence of diabetes and impaired glucose tolerance: The Australian diabetes, obesity and lifestyle study. Diabetes Care, 25, 829-834. https://doi.org/10.2337/ diacare.25.5.829

Fahlbusch, K.-G., Hammerschmidt, F.-J., Panten, J., Pickenhagen, W., Schatkowski, D., Bauer, K., Garbe, D. and Surburg, H. (2003). Flavors and fragrances. Ullmann's Encyclopedia of Industrial Chemistry. doi.org/10.1002/14356007.a11_141

Granados-Vallejo, M., Espinosa-Andrews, H., Guatemala-Morales, G.M., Esquivel-Solis, H. and Arriola-Guevara, E. (2019). Oxidative stability of green coffee oil (Coffea arabica) microencapsulated by spray drying. Processes, 7(10), 734. https:// doi.org/10.3390/pr7100734

Hien, T.T., Nhan, N.P.T., Trinh, N.D., Ho, V.T.T. and Bach, L.G. (2018). Optimizing the pomelo oils extraction process by microwave-assisted hydrodistillation using soft computing approaches. Solid State Phenomena, 279, 217-221. https:// doi.org/10.4028/www.scientific.net/SSP.279.217

Joy, P.P., Skaria, B.P., Mathew, S., Mathew, G. and Joseph, A. (2006). Lemongrass: the fame of Cochin. Indian Journal of Arecanut, Spices and Medicinal Plants, 8(2), 55-64.

Khanuja, S.P.S., Shasany, A.K., Pawar, A., Lal, R.K.,
Darokar, M.P., Naqvi, A.A., Rajkumar, S., Sundaresan, V., Lal, N. and Kumar, S. (2005). Essential oil constituents and RAPD markers to establish species relationship in Cymbopogon Spreng. (Poaceae). Biochemical Systematics and Ecology, 33(2), 171-186. https://doi.org/10.1016/ j.bse.2004.06.011

Kumar, A., Malik, F., Bhushan, S., Sethi, V.K., Shahi, A.K., kaur, J., Taneja, S.C., Qazi, G.N. and Singh, J. (2008). An essential oil and its major constituent isointermedeol induce apoptosis by increased expression of mitochondrial cytochrome $\mathrm{c}$ and apical death receptors in human leukaemia HL-60 cells. Chemico-Biological Interactions, 171(3), 332-347. https://doi.org/10.1016/j.cbi.2007.10.003

Lasekan, O. and Lasekan, A. (2012). Flavour chemistry of mate and some common herbal teas. Trends in Food Science and Technology, 27(1), 37-46. https:// doi.org/10.1016/j.tifs.2012.05.004

Lonkarbr, P., Chavanbr, U., Pawarbr, V. and Amarowicz, V. (2013). Studies on preparation and preservation of lemongrass (Cymbopogon flexuosus (steud) wats) powder for tea. Emirates Journal of Food and Agriculture, 25(8), 585. https:// doi.org/10.9755/ejfa.v25i8.15218

Miao, S. and Roos, Y.H. (2004). Nonenzymatic browning kinetics of a carbohydrate-based lowmoisture food system at temperatures applicable to spray drying. Journal of Agricultural and Food Chemistry, 52, 5250-5257. https://doi.org/10.1021/ jf049706t

Mohamed Hanaa, A.R., Sallam, Y.I., El-Leithy, A.S. and Aly, S.E. (2012). Lemongrass (Cymbopogon citratus) essential oil as affected by drying methods. Annals of Agricultural Sciences, 57(2), 113-116. https://doi.org/10.1016/j.aoas.2012.08.004

Nunes, I.L. and Mercadante, A.Z. (2007). Encapsulation of lycopene using spray-drying and molecular inclusion processes. Brazilian Archives of Biology and Technology, 50, 893-900. https:// doi.org/10.1590/S1516-89132007000500018

Obón, J.M., Castellar, M.R., Alacid, M. and FernándezLópez, J.A. (2009). Production of a red-purple food colorant from Opuntia stricta fruits by spray drying and its application in food model systems. Journal of Food Engineering, 90(4), 471-479. https:// doi.org/10.1016/j.jfoodeng.2008.07.013

Quek, S.Y., Chok, N.K. and Swedlund, P. (2007). The physicochemical properties of spray-dried watermelon powders. Chemical Engineering and Processing: Process Intensification, 46(5), 386-392. https://doi.org/10.1016/j.cep.2006.06.020 
Rajabi, H., Ghorbani, M., Jafari, S.M., Sadeghi Mahoonak, A. and Rajabzadeh, G. (2015). Retention of saffron bioactive components by spray drying encapsulation using maltodextrin, gum Arabic and gelatin as wall materials. Food Hydrocolloids, 51, 327-337. https://doi.org/10.1016/ j.foodhyd.2015.05.033

Rulkens, W.H. and Thijssen, H.A.C. (2007). The retention of organic volatiles in spray-drying aqueous carbohydrate solutions. International Journal of Food Science and Technology, 7(1), 95$105 . \quad$ https://doi.org/10.1111/j.13652621.1972.tb01644.x

Saenz, C., Tapia, S., Chavez, J. and Robert, P. (2009). Microencapsulation by spray drying of bioactive compounds from cactus pear (Opuntia ficus-indica). Food Chemistry, 114(2), 616-622. https:// doi.org/10.1016/j.foodchem.2008.09.095

Sarpong, F., Zhou, C., Bai, J., Amenorfe, L.P., Golly, M.K. and Ma, H. (2019). Modeling of drying and ameliorative effects of relative humidity $(\mathrm{Rh})$ against $\beta$-carotene degradation and color of carrot (Daucus carota var.) slices. Food Science and Biotechnology, 28, 75-85. https://doi.org/10.1007/s10068-018-04573

Weishemier, V., Miron, D., Silva, C.B., Guterres, S.S. and Schapoval, E.E.S. (2010). Microparticles containing lemongrass volatile oil: Preparation, Characterization and Thermal Stability. Pharmazie, 65, 885-890. https://doi.org/10.1691/ph.2010.0139

Skaria, B.P., Joy, P.P., Mathew, S. and Mathew, G. (2006). 24-Lemongrass. In Peter, K.V. (Ed.), Handbook of Herbs and Spices, p. 400-419. Woodhead Publishing. https:// doi.org/10.1533/9781845691717.3.400

Sun, X., Cameron, R.G. and Bai, J. (2020). Effect of spray-drying temperature on physicochemical, antioxidant and antimicrobial properties of pectin/ sodium alginate microencapsulated carvacrol. Food Hydrocolloids, 100, 105420. https://doi.org/10.1016/ j.foodhyd.2019.105420

Tajidin, N.E. (2012). Chemical composition and citral content in lemongrass (Cymbopogon citratus) essential oil at three maturity stages. African Journal of Biotechnology, 11, 2939. https://doi.org/10.5897/ AJB11.2939

Tomaino, A., Cimino, F., Zimbalatti, V., Venuti, V., Sulfaro, V., De Pasquale, A. and Saija, A. (2005). Influence of heating on antioxidant activity and the chemical composition of some spice essential oils. Food Chemistry, 89(4), 549-554. https:// doi.org/10.1016/j.foodchem.2004.03.011
Tonon, R.V., Brabet, C. and Hubinger, M.D. (2010). Anthocyanin stability and antioxidant activity of spray-dried açai (Euterpe oleracea Mart.) juice produced with different carrier agents. Food Research International, 43(3), 907-914. https:// doi.org/10.1016/j.foodres.2009.12.013

Turek, C. and Stintzing, F.C. (2013). Stability of essential oils: A review: stability of essential oils. Comprehensive Reviews in Food Science and Food Safety, 12(1), 40-53. https://doi.org/10.1111/15414337.12006

Veiga, R.D.S.D., Aparecida Da Silva-Buzanello, R., Corso, M.P. and Canan, C. (2019). Essential oils microencapsulated obtained by spray drying: A review. Journal of Essential Oil Research, 31(6), 457-473.

https:// doi.org/10.1080/10412905.2019.1612788

Xu, D.-H., Huang, Y.-S., Jiang, D.-Q. and Yuan, K. (2013). The essential oils chemical compositions and antimicrobial, antioxidant activities and toxicity of three Hyptis species. Pharmaceutical Biology, 51(9), 1125-1130.

https:// doi.org/10.3109/13880209.2013.781195

Zanetti, M., Carniel, T.K., Dalcanton, F., dos Anjos, R.S., Gracher Riella, H., de Araújo, P.H.H., de Oliveira, D. and Antônio Fiori, M. (2018). Use of encapsulated natural compounds as antimicrobial additives in food packaging: A brief review. Trends in Food Science and Technology, 81, 51-60. https:// doi.org/10.1016/j.tifs.2018.09.003 